\title{
Recycling of scrap tyres
}

\author{
Sudha Rani, Rajesh Agnihotri* \\ Applied Science Department, Kurukshetra University, Haryana, India
}

\section{Email address:}

Sbachhraj692@gmail.com (S. Rani), agnihotrir72@gmail.com (R. Agnihotri)

\section{To cite this article:}

Sudha Rani, Rajesh Agnihotri. Recycling of Scrap Tyres. International Journal of Materials Science and Applications. Vol. 3, No. 5, 2014, pp. 164-167. doi: 10.11648/j.ijmsa.20140305.16

\begin{abstract}
Environmental distress harms concerning the possibility of using tyre rubber waste as raw materials for the research of liquid This research explain the use of tyre pyrolysis oils by solving the difficulty of waste tyre removal. In this study pyrolysis of scrap tyres was approved in controlled environment in Rotary bed horizontal batch reactor of 10T capacity at a high temperature of $430^{\circ} \mathrm{C}$ to create pyrolytic oil, non-condensable gases, steel wires and char.This paper also provides the physical properties of pyrolytic oil and compare with the diesel oil.
\end{abstract}

Keywords: Pyrolysis, Tyre Pyrolysis Oil, Scrap Tyres

\section{Introduction}

Dumping of waste rubber products is becoming an environmental challenge in several developing countries due to their non-biodegradability characteristic. Majority of waste rubber products are generated from damaged or scratched automotive tyres and industrial conveyor belts [1]. Until now the way of degrading or recycling them is a major environmental challenge. Tyres made of complex mixtures of very different materials which include several rubbers, carbon black, steel cord and other organic and inorganic minor components [2]. The increasing amount of tyre rubber dissipate is generating more and more ecological problems worldwide. The current rate of monetary growth is unbelievable without reduction of fossil energy like crude oil, natural gas and coal. Appropriate waste management is an additional important aspect of sustainable growth. Rubber misuse represent a substantial part of municipal waste, furthermore a large amounts of waste arise as a by-product or faulty product in industry and agriculture [3]

The quick development of the automobile industry and superior standard of living of people in India, the quantity of autos increased rapidly. Now India is facing the ecological problems related to the removal of large-scale waste tyres. Near about 1.5 billion waste tyres are generated by the world annually, in which $40 \%$ in rising markets such as China, India, South Africa, South East Asia, South America and Eastern Europe etc. and more than 33 million vehicles added to the Indian Roads in the last three years. Now, in accordance with the statistic data, 80 million scrap tyres were created in 2002, and with $12 \%$ of enlargement rate every year, the whole number of abandoned tyres reached 120 million in 2005 and 200 million in 2010 [4]. However with the deal of vast number of waste tyres has become a vital problem of environment in India? Pyrolysis process becomes an alternative of waste-to-energy technology to deliver bio-fuel to replace fossil fuel. Waste tyre is investigated in this research in the available technology. The advantage of the pyrolysis process is its ability to handle unsort and dirty rubber. The pre-treatment of the material is easy. Tyre is needed to be shredded. Pyrolysis is also neither toxic nor environmental harmful emissions unlike incineration occure.[5].

\subsection{Difficulties with the Waste Tyres}

Tyres are made of vulcanized rubbers (with styrene butadiene (SBR), natural rubber (NR) and polybutadiene (BR), carbon black, steel, textile cord and little amount of other additives. The dumping of waste tyres is one of the main environmental issues all over the world. The toughness and resistance of the over material to biological removal make their removal and reprocessing difficult. Greater than $3.4 \times 10^{6}$ tonnes of end-of-life tyres are generated yearly in European Union, $2.5 \times 10^{6}$ tonnes in North America and $1 \times 10^{6}$ tonnes in Japan. Though the measure of scrap tyres formed in India does not exactly exists but the growing trend of use of road moving force will certainly generate a problem of removal in very near future. In the year 2008 India had over 100 million vehicles 
recorded on its roads. This was an enlargement of about $100 \%$ in the last 9 years [6].

\section{Methods of Waste Tyres Recycling}

The feasible way of waste tyres recycling are:

\subsection{Retreading and Reusing of Tyres}

In this method, the old tread is bufferd away from a tyre to be remoulded and a new tread rubber strip is compound to the old carcass by using specilized machinery. The financially viable prospective of the treatment is main benefit and the quality of the products is a problem of retreading.

\subsection{Recycling by Production of Ground Rubber for Use in Further Applications}

By mechanical or by cryomechanical (temperature range of rubber lies between -60 to $-100^{\circ} \mathrm{C}$ ) milling of tyres the earth rubber of different sizes can be formed. These resources can be used in further applications, like: as element in asphalts, carpets, sport surfaces and kids playing fields. By the use of cryomechanical technology it is attainable to get a very fine powder, which could be handling as reinforcement in latest rubber products. By the some properties of rubber equipment and the lack of straight air emissions are the main advantages. By, the high using up of energy, liquid nitrogen in the cryomechanical method and the partial market for the products are the main drawbacks of the technique.

\subsection{Reclaiming Rubber Raw Materials}

Reclaiming of scrap rubber products have been made since 1910. By, the using of rubber products through the processing and moulding are crosslinked, so they cannot be again and again softened or remoulded by heating. Scrap rubber reclaiming of products means the substitute of a three dimensionally interlinked, insoluble and infusible well-built thermoset polymer to a two dimensional, flexible, plastic, processable and vulcanizable polymer simulating several of the propertie of virgin rubber. Reclaiming of scrap rubber is more complex than reclaiming of thermoplastics in this case. Different methods and processes for reclaiming waste rubber were developed. But the important of them are: the mechanical shearing process and thermomechanical reclaiming by use of different chemical agents, microwave reclaiming, ultrasonic reclaiming, and pyrolysis of waste rubber and reclaiming by renewable resource materials and reclaiming by biotechnological processes.

The major harms which reclaim methods face is the suitability of reclaim by rubber industry as a raw material. It has two major factors in which it depends:

- The superiority of reclaim products considered by their properties balance to the properties of virgin raw materials
- The expenses of reclaim compared to the expenses of virgin rubber.

Recycling of scrape tyres by reclaiming need more research to achieve better quality of reclaim and additional cost-effective reclaiming process.

\subsection{Pyrolysis}

Tyre pyrolysis (thermal breakdown in the absence of oxygen) is presently getting renewed attention. An environmentally striking method offered by the pyrolysis process during the recycling of tyres. Various products are obtained during the tyre pyrolysis process such as: Solid char (30-40 wt \%), liquid residue (40-60 wt \%) and gases (5$20 \mathrm{wt} \%$ ). The solid residue which is initially present in the tyre contains carbon black and the mineral matter. This solid char may be used in the rubber industry as reinforcement as activated carbon or as smokeless fuel. The extremely complex mixture of organic component is obtained by the liquid product. So, the oils which have been obtained by the liquid product can be used directly as fuels, petroleum refinery feedstock or a source of chemicals. In the pyrolysis process non-condensable organics like $\mathrm{H}_{2}$, $\mathrm{H}_{2} \mathrm{~S}, \mathrm{CO}, \mathrm{CO}_{2}, \mathrm{CH}_{4}, \mathrm{C}_{2} \mathrm{H}_{4}, \mathrm{C}_{3} \mathrm{H}_{6}$ etc are also present which gives the gaseous fraction. The little bit part of gas can be used as fuel in the pyrolyses process.

For increasing the economical effectiveness and amplification of markets for pyrolysis products, additional research is required in the field of method conditions, optimisation, and product characterisation and treatment.

\section{Combustion}

\subsection{Incineration}

Waste tyres can be used straightly as fuels in the incinerators. In this method electrical power can be generated by incineration of waste tyres. The initial cost of this process.is very high and after processing it cause a lot of pollution. Due to their elevated heating rate scrap tyres are excellent materials for energy recovery. The use of tyres directly as fuel in incinerators has the various advantages: abridged power-production costs, maximum heat recovery, and environmentally acceptable process. The major drawbacks are: no material improvement, large capital cost, need for flue gas cleaning, $\mathrm{CO}_{2}$ emission, high operating costs. In cement kilns the scrap tyres are used as a fuel. Further research works is required for obtaining environmental impacts of this method, mainly from the view of polycyclic aromatic hydrocarbon (PAH) emissions [7].

\section{Experimental}

\subsection{Pyrolysis Unit}

Pyrolysis is the chemical decomposition of organic material at elevated temperature in the absence of oxygen or any other reagents, except possibly steam.about $430^{\circ} \mathrm{C}$ 
in the horizontal batch process system.

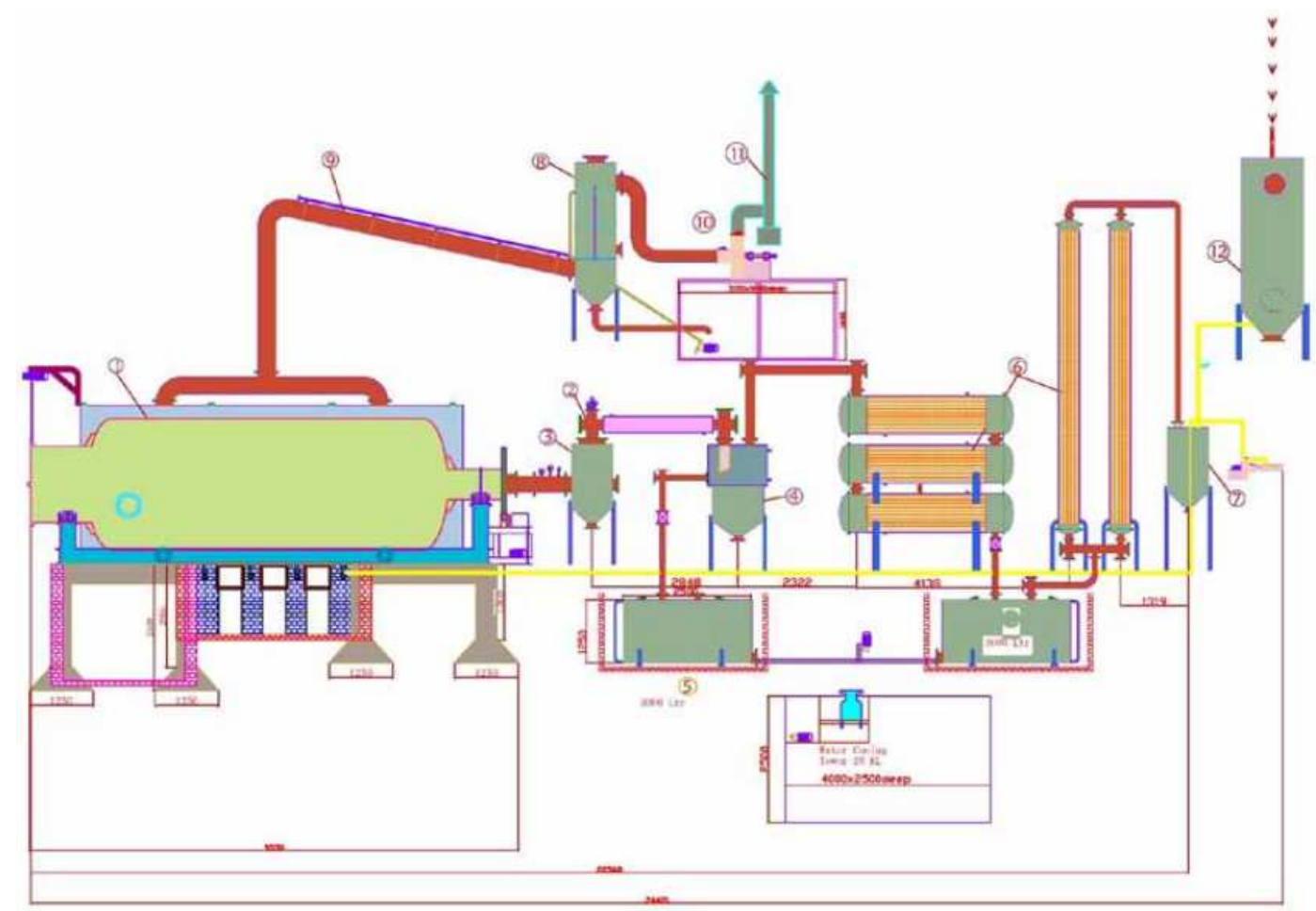

Fig. Waste tyre recycling pyrolysis plant

Technical detail of 10 ton Pyrolysis Plant
1. Main (10 ton) Reactor
2. Vertical Condenser
3. Insulation Tank.
4. Water seal tank
5. Gas tank
7. Water coolent pipe
8. Scrubber pipe set
6. Oil tank
10. Draft fan
11. Hoist
9. Scrubber tank
12. Chain block

The waste tyres are fed in the horizontal batch reactor $10 \mathrm{~T}$ capacity at a time as shown in figure and heat is supplied by mean of oil and sometimes by wood under controlled condition of temperature and pressure.the process will bring in absence of oxygen and convert in to vapour and gases. These vapour and gases come in to seprator where heavy oil fraction is seprated from gases In the recycling of tyre by the pyrolysis will be used to the tyres into fuel oil (40 to $45 \%$ ), fuel gas ( 5 to $8 \%$ ), solid char (steel wire 15 to $20 \%$ ) and carbon black.(30 to $35 \%$ ) etc are obtained. Unlike researchers conducted different pyrolysis experiments for waste tyre recycling. According to Andrian M Cunliffe [8] use pyrolysed tyres in a static bed batch reactor of inner diameter $24 \mathrm{~cm}$ and depth $36 \mathrm{~cm}$ with a feed stoke of $3 \mathrm{~kg}$ of tyres for $120 \mathrm{~s}$ at temperatures of $450,475,500,525,560$ and $600{ }^{\circ} \mathrm{C}$. By the study of Williams et al [9] use operated batch pyrolysis unit with $1015 \mathrm{~kg}$ of tyre feed at a temperature of $950{ }^{\circ} \mathrm{C}$. C. Roy [10] accepted out Pyrocycling of tyres at a temperature of $480-520{ }^{\circ} \mathrm{C}$ at a pressure lower than $10 \mathrm{kPa}$. And Tiejun Wang [11] in his experiment of vacuum pyrolysis of waste tyres with basic additives pyrolysed $100 \mathrm{~g}$ of tyre granules mixed with $3.0 \mathrm{~g}$ of additives in a stainless steel pyrolysis reactor with inner diameter $32 \mathrm{~mm}$ and depth $120 \mathrm{~mm}$.

\section{Yield of Pyrolysis Process}

\subsection{Pyrolysis Oil (Fuel Oil)}

The main product of tyre pyrolysis process is pyrolysis oil which is widely used for in industrial and commertial purposes. Tyre produced mainly 40 to $45 \%$ oil in the recycling of tyre pyrolysis process which is used as a fuel component for heating in fire chamber. Pyrolysis oil have flash Point between $66^{\circ} \mathrm{C}$. Purest quality of pyrolysis oil equivalent to industrial diesel: selling price equivalent to industrial diesel light diesel oil (LDO)

\subsection{Carbon Black}

The other important product of pyrolysis plant was carbon black referred as "charcoal"(by 30 to $35 \%$ of total quantity) carbon black in Industrial and commercial use.

\subsection{Steel Wire}

Waste tyres also contain fibers and steel wire. Shredded tyres mainly contain of the steel and sometimes the majority of the fiber removed. The steel wire percentage in most of the tyre is 15 to $20 \%$ can be separated from the carbon black with magnets for recycling after pyrolysis process \& sold to the steel trader. 


\subsection{Hydrocarbon Gas}

The slighter molecules ultimately vaporize and way out from the reactor. These vapors could burn directly to create power or condensed to an oily type liquid, which do not condenced at room temerature and pressure. Which can be generally used as a fuel?. Some molecules would be small to condense. They exist as a gas which can be used as a fuel. In this process 5 to $8 \%$ gas will exist of total quantity feed.

\section{Results and Discussion}

Tyre oil produced by the pyrolysis method was tested in the laboratory as per IS 1448 for purpose of its physical properties. The liquids obtained are dark blacklbrown colored products, similar to petroleum fractions as shown in table. The Kinematic viscosity of the tyre oil is 2-8 cSt. For some engines it is advantageous to specify a minimum viscosity because of power loss due to injection pump and injector leakage. Maximum viscosity, on the other hand, is limited by considerations involved in engine design and size, and the characteristics of the injection system. The flash point of the tyre-derived oil $66^{\circ} \mathrm{C}$. The flash point as specified is not directly related to engine performance. It is however, of importance in connection with legal requirements and safety precautions involved in fuel handling and storage, and are normally specified to meet insurance and fire regulations. The sulphur content of the tyre oil is $0.04 \%$ which is less than found by other researchers. The sulphur content is found less than that of a light to medium fuel oil. The ash percentage is $0.05 \%$. Ashforming materials may be present in fuel oil in two forms: (1) abrasive solids and (2) soluble metallic soaps. Abrasive solids contribut to injector, fuel pump, piston and ring wear, and also to engine deposits. Soluble metallic soaps have little effect on wear but may contribute to engine deposits. Table shows the attention of the physical property of the light diesel oil.and compare with the properties of diesel oil.

Table. Comparison of properties of LDO and Diesel

\begin{tabular}{llll}
\hline S. No. & Properties & Diesel Sample & LDO \\
\hline & & & \\
1. & Ash, percent by mass, & Nil & $0.04 \%$ \\
2. & Max & $42^{0} \mathrm{C}$ & $35^{0} \mathrm{C}$ \\
3. & Flash point & 10800 & 10540 \\
4. & Gross Calorific value & 2.37 & 4.25 \\
5. & Viscosity (cSt) & 0.32 & 0.049 \\
& Sulphur & .8 & \\
6. & Water Content \% by & Nil & 0.37 \\
7. & volume (max) & 5 deg C & 7 deg C \\
8 & Cloud point & Nil & Nil \\
\hline
\end{tabular}

\section{Conclusion}

Recycling of scrap tyres produce oil that can be fullfill the requirenment for industrial fuel, foundries and bolilers in power plants due to their higher viscosity, higher gross calorific value, low ash percentage and sulphur content. However the higher kinematic viscosity and higher density of tyre oil suggest that behaviour of tyre oil in the IC (internal combustion) engine can be studied through the tyre oil. Recycling of scrap tyre pyrolysis gives comparable efficiency to diesel oil in medium to high load but it has been question on the desulfurization process. More improvement in fuel quality in term of desulfurization, reduction in viscosity is required for tyre oil as an alternate fuel for diesel engine.

\section{Acknowledgement}

I would like to thank Mr. Ravi Gupta, Kurukshetra for their valuable support and time in producing Tyre pyrolysis oil as per the requirement. I would also thankful to Mr. Subhash of Vikas laboratory, Pipli (Kurukshetra) for their valuable support and time in characterization of Tyre pyrolysis oil.

\section{References}

[1] Jefrey Pilusa and Edison Muzenda "Qualitative Analysis of Waste Rubber -Derived Oil as an Alternative Diesel Additive" (2013), pp 1-5.

[2] M. P. Hirenkumar, and M.P. Tushar, "Emission Analysis of a Single Cylinder Fuelled with Pyrolysis Oil Diesel and its Blend with Ethanol," IJEST, vol. 4, 2012, pp. 2834 -2838.

[3] Ewa Rostek, Krzysztof Biernat" Thermogravimetry as a Research Method in the Transformation Processes of Waste Rubber and Plastic Products for Energy Carriers" (2013), pp 163-171.

[4] Ganapathi Malarvizhi et al. "A Study on Recycling Of Crumb Rubber and Low Density Polyethylene Blend on Stone Matrix Asphalt" (2012) pp, 1-16.

[5] C. Wongkhorsub, N. Chindaprasert "A Comparison of the Use of Pyrolysis Oils in Diesel Engine" (2013), pp 350-355

[6] Bhatt Prathmesh M, Patel Paresh D, "Suitability Of Tyre Pyrolysis Oil (TPO) As An Alternative Fuel For Internal Combustion Engine", (2012), pp 61-65.

[7] M. Juma et al "Pyrolysis and Combustion of Scrap Tyre" (2006), pp 15-26.

[8] Cunnliffe A M, Williams P T. Composition of oil derived from the batch pyrolysis of tyres. Journal of Analytical and Applied Pyrolysis. 1997; 44: 131-152.

[9] Williams P T, Bottril R P, Cunliffe A M. Combustion of tyre pyrolysis oil. Trans IChme.1998; 76(B).

[10] Roy C, Chaala A, and Darmstadt H. The Vacuum Pyrolysis of Used Tyres End use of oil and carbon black product. Journal of Analytical and Applied Pyrolysis.1998; 51: 201221.

[11] Wang Tiejun, Zhang Xinghua. Vacuum pyrolysis of scrap tyres with basic additives. Waste Management.2007; 28: 2301-2310. 